\title{
The effects of thinning intensity and tree size on the growth response to annual climate in Cedrus atlantica: a linear mixed modeling approach
}

\author{
Joannès Guillemot • Etienne K. Klein • Hendrik Davi • \\ François Courbet
}

Received: 13 March 2014 / Accepted: 28 January 2015 / Published online: 6 March 2015

(C) INRA and Springer-Verlag France 2015

\begin{abstract}
- Key message With a retrospective growth analysis over 20 years, we showed that silviculture (in particular thinning) of Cedrus atlantica (Manetti) could to some extent mitigate the effects of drought episodes. Severe reductions of density resulted in faster recovery of radial growth after severe drought episodes.

- Context Climate change is expected to increase the frequency and the intensity of drought in southern Europe. Silviculture could help in mitigating the effects of water deficit on forests.
\end{abstract}

\section{Handling Editor: Andreas Bolte}

Contribution of the co-authors J.G. conducted the analyses and wrote the paper, F.C. designed the experiment and supervised the work, E.K.K. provided support in statistical analyses, H.D. provided support in discussing ecophysiological aspects; all authors corrected the manuscript.

Electronic supplementary material The online version of this article (doi:10.1007/s13595-015-0464-y) contains supplementary material, which is available to authorized users.

J. Guillemot $\cdot$ H. Davi $\cdot$ F. Courbet $(\bowtie)$

INRA, UR629, Ecologie des Forêts Méditerranéennes (URFM), 84914 Avignon, France

e-mail: francois.courbet@avignon.inra.fr

J. Guillemot

e-mail: joannes.guillemot@gmail.com

H. Davi

e-mail: hendrik.davi@avignon.inra.fr

E. K. Klein

INRA, UR546, Biostatistique et Processus spatiaux (BioSP), 84914 Avignon, France

e-mail: etienne.klein@avignon.inra.fr

Present Address:

J. Guillemot

Laboratoire Ecologie, Systématique, Evolution (UMR 8079 -

Université Paris Sud, AgroParisTech, CNRS), Bâtiment 362,

91405 Orsay, France
- Aim The aim of this study is to assess the effect of thinning intensity on the climate-growth relationship of different crown classes in Cedrus atlantica (Manetti).

- Material and methods A 20-year annual survey was conducted on plots managed under contrasted thinning regimes in a site of the southern French Alps. Using a linear mixed modeling approach, we evaluated the modulation of the growth response to annual climate by thinning (climate $\times$ thinning interaction effect) during the experiment. The effect of thinning on the growth sensitivity to annual climate and the effect of thinning on the growth response to pointer years were also quantified.

- Results The highest intensity of thinning significantly changed the climate-growth relationship of the two most dominant crown classes. Heavy thinning reduced the impact of negative pointer years during a period of 4-5 years and improved the post-drought recovery for a decade. Heavily thinned plots and dominant crown classes had significantly higher relative growth sensitivities to annual climate over the studied period.

- Conclusions Forest management has the potential to reduce the effect of water deficit on the growth of Atlas cedar stands. We provide keystones for future silvicultural guidelines, in the context of a larger introduction of $C$. atlantica in the French territory.

Keywords Forest management $\cdot$ Crown classes $\cdot$ Stand density $\cdot$ Water deficit $\cdot$ Resilience $\cdot$ Competition . Dendrochronology

\section{Introduction}

Climate change is expected to affect greatly the functioning of European forest ecosystems, especially through a greater frequency and intensity of drought. In the Mediterranean area, 
drought is already the principal factor limiting tree growth and survival (Andreu et al. 2007). Understanding how water deficits affect Mediterranean forests is therefore important for predicting the consequences of increased drought in this region as well as the future consequences of climate change for northern zones. Indeed, 60 to $80 \%$ of the French metropolitan territory may experience a Mediterranean type climate by the end of the twenty-first century (Roman-Amat 2007). The acclimation of existing forest stands to increasing drought relies on different physiological adjustments, among which leaf area reduction seems of particular importance over the long term (Martin-StPaul et al. 2013), and may be related to changes in stem density (Barbeta et al. 2013). Thinning operation, which modulates stem density and stand vertical structure, can thus accelerate this stand acclimation and has been reported to improve tree resistance to drought stress (Misson et al. 2003) and post-drought resilience (Martín-Benito et al. 2008; Sohn et al. 2013). Silviculture is therefore discussed as an important option to mitigate the negative impact of water deficit on forest (Guillemot et al. 2014).

The annual tree growth is considered as an efficient proxy for tree vitality (Dobbertin 2005) and appears to be modulated by the combined effects of annual climate and competition intensity. These dependencies have often been studied separately. The effect of the annual climate on tree radial growth has been widely investigated to gain insight into the autecology of tree species (e.g., Lebourgeois et al. 2005) or the drivers of forest dieback (Williams et al. 2013). This approach generally neglects the effects of competition on tree growth. Contrastingly, empirical tree growth models aim to predict the long-term growth response to thinning, i.e., to competition modulation. In this second approach, the annual effect of climate on growth is either neglected in a multi-year modeling step or controlled by adding explicit climate variables to the models (Le Goff and Ottorini 1993; Mehtätalo et al. 2014).

Few studies have explicitly investigated the short (annual) and long (decadal) term effects of the interaction between competition and annual climate conditions on tree growth. The effect of competition intensity on the climate-growth relationship was often based on experiments that did not reproduce actual silvicultural guidelines: studies were conducted in stands that had not been thinned for decades (Gea-Izquierdo et al. 2009; Martínez-Vilalta et al. 2012), in stands thinned once (Misson et al. 2003) and in stands lightly thinned (Piutti and Cescatti 1997; Timbal 2002; Kohler et al. 2010; but see Olivar et al. 2013 and Sohn et al. 2013). As a consequence, several important aspects of management impact on forest functioning were overlooked: (i) the short- and medium-term effects of thinning, (ii) the cumulative effect of successive thinning and (iii) the prospective analysis of the effect of thinning intensities beyond the current guidelines. Moreover, most of the previous studies focused on the growth response of dominant trees, which is not always representative of the functioning of the entire stand (De Luis et al. 2009; Mérian and Lebourgeois 2011). Conversely, annual size surveys allow the competition intensity to be quantified yearly, along with the assessment of the effect of social position on the tree growth responses.

The effect of thinning on the climate-growth relationship of trees has primarily been assessed using growth series standardized with mathematical functions fitted to data (e.g., Misson et al. 2003). This empirical detrending separates competition from annual climate effects, based on the expected frequency variations they induced on growth (year period for annual climate and decade period for competition). The sharp growth responses to thinning are then likely overlooked because the variation frequencies induced by the different factors (annual climate and thinning) overlap. Contrastingly, detrending based on individual growth models allows a competition-based standardization that accounts efficiently for the growth response to thinning (Piutti and Cescatti 1997). However, this latter approach often ignores the departure from the assumption of independent error terms induced by the multilevel (plot, tree, year) organization of tree-ring data, thus preventing valid statistical tests (Fortin et al. 2007). As a result, Miina (2000) suggested the use of linear mixed models (LMMs) for treering standardization. In this approach, the fixed part of the model incorporates the individual growth responses, whereas the random effects represent the hierarchical structure of the data. LMMs have recently been used to standardize tree-ring series (e.g., Martínez-Vilalta et al. 2012), but rarely to explicitly quantify the effect of thinning on the climate-growth relationship (Olivar et al. 2013).

In this paper, we present the results of a case study that was conducted to determine the short- and long-terms effects of thinning on the climate-growth relationship of trees from different crown classes. An experiment was conducted during 20 years, based on extensive surveys of plots under contrasted thinning treatments. Linear mixed models were used to disentangle the growth signals in the context of abrupt thinninginduced changes in the competition intensity. This study was conducted in an important Mediterranean species, Cedrus atlantica (Manetti). More than 20,000 ha are predominantly planted with $C$. atlantica in France (Courbet et al. 2007). In the context of climate change, a larger introduction of C. atlantica is now recommended by the French national guidelines (Roman-Amat 2007) but decline and mortality events have been recently reported in its native area (Allen et al. 2010; Linares et al. 2011), urging for deeper insight in Atlas cedar drought tolerance. We therefore aimed to answer the following questions: (1) Does a reduction in stand competition induced by thinning affect the climategrowth relationship of Atlas cedar? (2) How long after thinning do its effects persist? (3) Does social position affect the growth responses of Atlas cedar trees to annual climate? 


\section{Materials and methods}

\subsection{Study site}

The study site was selected to be homogeneous in terms of physical environment (slope, elevation, exposure, soil depth) and stand characteristics. The Mediterranean area displays a strong local heterogeneity of climate and soil (Ruffault et al. 2013) and the site was consequently limited to a small (1.5 ha) area. It was located on Mont Ventoux in the southern French Alps. This region has a Mediterranean mountain climate. The site ( $44^{\circ} 07^{\prime} 05^{\prime \prime} \mathrm{N}, 5^{\circ} 20^{\prime} 38^{\prime \prime} \mathrm{E}, 1170 \mathrm{~m}$ a.s.l.) is located at an altitude between two nearby stations of the national meteorological network $\left(44^{\circ} 09^{\prime} 00^{\prime \prime} \mathrm{N}, 5^{\circ} 19^{\prime} 06^{\prime \prime} \mathrm{E}, 1455 \mathrm{~m}\right.$ a.s.l. and $44^{\circ} 05^{\prime} 18^{\prime \prime} \mathrm{N}, 5^{\circ} 25^{\prime} 00^{\prime \prime} \mathrm{E}, 792 \mathrm{~m}$ a.s.l.). The values of the climatic variables at the study site were estimated from the datasets of these stations. The monthly average temperatures were calculated assuming a decrease in temperature proportional to altitude. The monthly average rainfall was calculated as the mean between the two stations. The mean annual rainfall over the 1989-2010 period was $1076 \mathrm{~mm}$, which is a high value for the Mediterranean climate context, but is the average within the natural range of this species (Benabid 1994). The Gaussen diagram shows one growth-limiting month during the summer (Fig. 1). The soil is a calcaric Leptosol, with a substantial gravel component resulting from the limestone substrate. As a result, the soil is permeable and has low water holding capacity $(30 \mathrm{~mm}$ to a depth of $25 \mathrm{~cm}$ of soil, the calcareous substrate prevents accurate estimation for the entire extent of the prospected soil).

\subsection{Experimental design}

The experiment was initiated in 1989 in a homogeneous and even-aged 25-year-old plantation, with an initial density of 2500 trees $\mathrm{ha}^{-1}$. The stand was divided into four contiguous plots ranging from 1200 to $1400 \mathrm{~m}^{2}$, each plot surrounded by a buffer zone (with a minimum thickness of $10 \mathrm{~m}$ ) to avoid edge effects. Every winter from 1989 to 2010, the stem circumference over bark $(\mathrm{CBH})$ of every tree was measured to the nearest millimeter at breast height $(1.3 \mathrm{~m})$, which had been previously marked with paint. We derived the annual basal area increments (BAIs) from the circumference measurements, assuming a circular cross-section of the trees. In 1989 , each tree was definitively assigned to one of 5 crown classes - dominant, co-dominant, intermediate, overtopped, and suppressed - based on its size, social rank, and distance to trees from the same crown class. Stem densities and average CBHs within each crown class were similar between plots whereas average $\mathrm{CBHs}$ generally differed significantly among the crown classes of each plot (Table 1). To ensure robust tests on the tree growth response dependencies, our analyses included a substantial number of trees per plot. Overall, 1391 trees have been measured and managed annually (Table 1).

The control plot (plot 4) was never thinned during the experiment, whereas plots 1 to 3 were managed with contrasted thinning intensities (Fig. 2). The first thinning consisted of removing one, two, or three crown classes in plot 3 (the most lightly thinned), 2 (the moderately thinned plot) or 1 (the most heavily thinned), respectively, starting with the most overtopped class. The second thinning consisted of removing the remaining most overtopped class in each managed plot (Table 2). Thinning treatment is defined as the number of crown classes remaining in the plot after thinning. The managed plots experienced therefore two different thinning treatments during the studied period, whereas the control plot only experienced the "5 crown classes" treatment (Table 2).

\subsection{Environmental homogeneity of the experiment}

Our experimental design did not include plot-level replications. For this reason, we carefully checked the homogeneity of the growth conditions among plots before the initiation of the experiment, using phytocentric methods (Skovsgaard and Vanclay 2008), in order to minimize the plot effects on growth not driven by the thinning treatment. The homogeneity of the physical environment was assessed in 1989, comparing: (i) site indexes, i.e., the top height values at an age of reference (Skovsgaard and Vanclay 2008). (ii) mean CBHs of the different crown classes, with one-way ANOVAs. Because no cutting occurred in the stand before 1991, these later tests compared the actual production of the 4 plots, from seedling plantation until the initiation of the experiment.
Fig. 1 Left Geographical location of the study site. Right Gaussen diagram (line mean monthly temperatures, bars cumulative monthly precipitations). Data are averaged over the last 30 years. Months with a mean rainfall less than twice the mean temperature are considered limiting for vegetal development

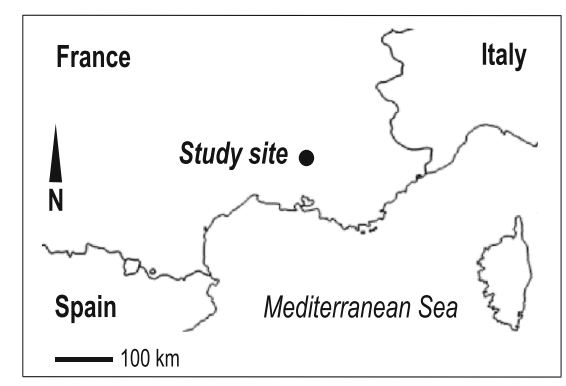

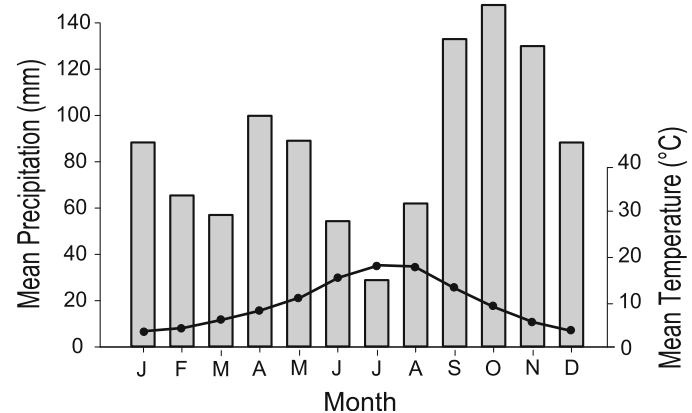


Table 1 Average circumferences over bark $(\mathrm{CBH})$ of the crown classes and site indexes, measured in 1989. ANOVA analysis revealed no significant differences in the average $\mathrm{CBH}$ of a given crown class between plots or in the total stand average $\mathrm{CBH}$ between plots. Within plots, crown classes generally differed in mean circumferences, except for values with the same letter (pairwise $t$ tests at the $5 \%$ probability level). Site index is the top height at the age of 25 years. Values in parenthesis are the number of trees

\begin{tabular}{llllll}
\hline & & Plot 1 & Plot 2 & Plot 3 & Plot 4 \\
\hline Mean CBH (cm) & Dominant class & $474.5(33)$ & $472.9(35)$ & $470(32)$ & $420.7(34)$ \\
& Co-dominant class & $446.5(36)$ & $409.5^{\mathrm{a}(38)}$ & $42.7(29)$ \\
& Intermediate class & $398.2(88)$ & $400.6^{\mathrm{a}}(91)$ & $396.3(79)$ & $426.1(35)$ \\
& Overtopped class & $368.5(94)$ & $352.1(105)$ & $356.6^{\mathrm{b}}(87)$ & $302.5(76)$ \\
& Suppressed class & $356.4(109)$ & $344.3(111)$ & $358.1^{\mathrm{b}}(100)$ & $327.9(96)$ \\
Site index $(\mathrm{m})$ & TOTAL & $377.2(360)$ & $358.5(380)$ & $369.3(332)$ & $354.5(319)$ \\
& & 9.8 & 9.9 & 9.7 & 9.9
\end{tabular}

\subsection{Statistical analyses}

\subsubsection{Tree growth modeling}

We used a linear mixed model (Littell et al. 2006) to detrend the growth signal, i.e., to separate the relative effects of the tree and plot-level variables on tree growth and isolate the inter-annual variability component from the raw growth signal. The fixed effects were selected from a large collection of dendrometric variables, which included tree-level and standlevel measurements as well as relative indexes measuring tree situation compared with stand characteristics (the variables not retained in the final model are listed in Table S1 of the supplementary material). Fixed-effect variables were logtransformed or included with quadratic effects after visual assessment of bivariate plots. The model selection was based on the protocol described in Zuur et al. (2009). We started with a model including all the considered fixed-effect variables along with their second order interactions, in order to find the optimal structure of the random component. In this step, the correlation among annual observations made on a given tree was accounting for by testing different autoregressive moving average (ARMA) models as the covariance structure for the error terms. Additionally, the heteroscedasticity of the data was considered by assuming the residual variance to be proportional to different power function of the predicted BAIs. In a second step, the optimal fixed structure was selected and the importance of random effects on covariate slopes was tested. The model selection was based on the Akaike's Information Criterion (AIC) and likelihood ratio tests were performed to check for significant model improvements.
Fig. 2 Temporal changes in the stand basal area of the study plots

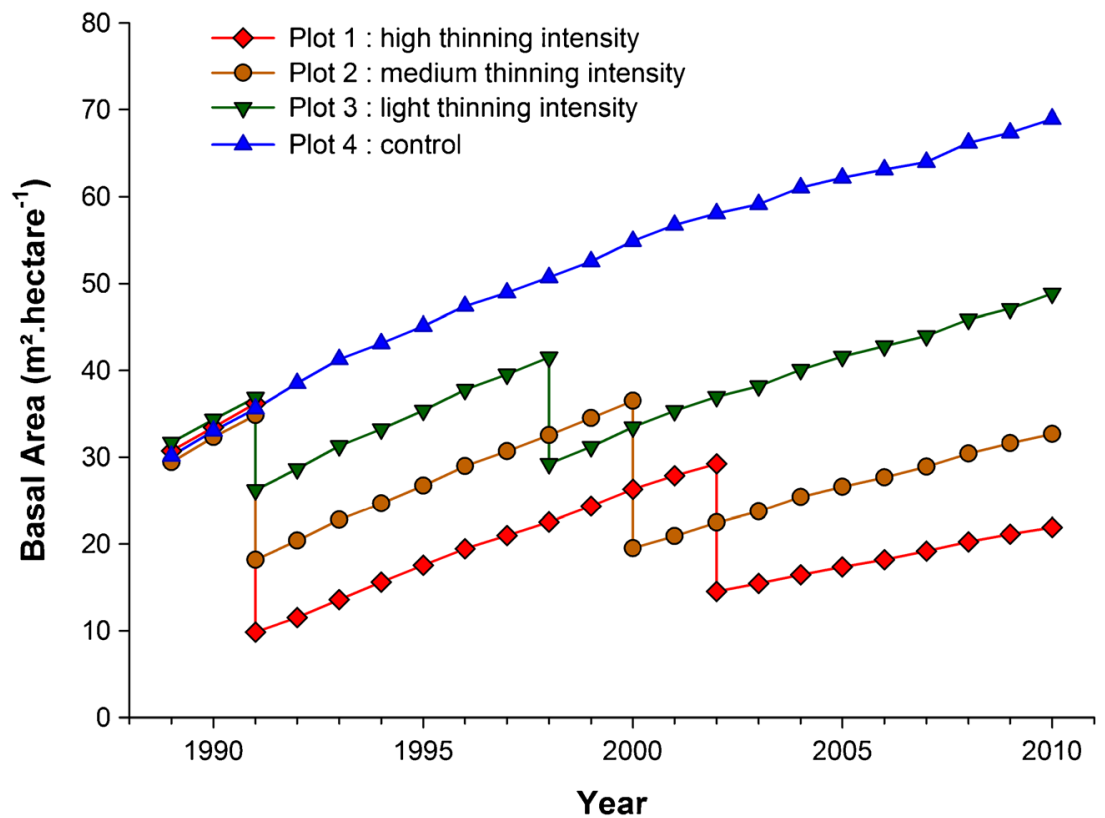




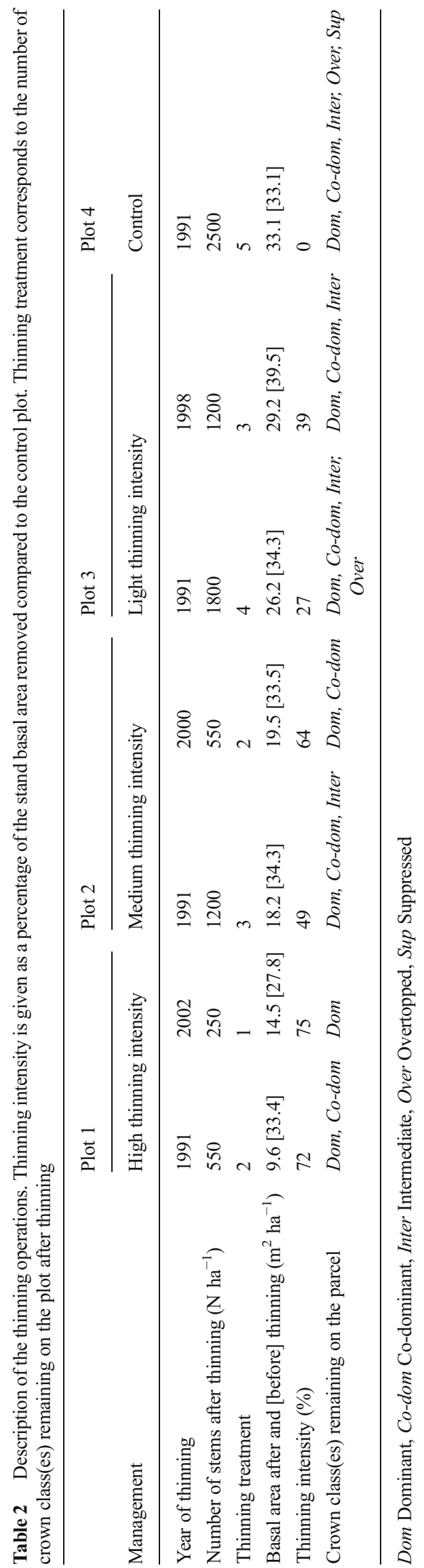


The dependent variable was the basal area increment $\mathrm{BAI}_{\mathrm{y}}$, i,c,k $\left(\mathrm{mm}^{2}\right.$ year $\left.^{-1}\right)$ of year $y$, measured on tree $i$ from a crown class $c$ in a plot $k$. The retained final model is written in Eq. 1.

$$
\begin{aligned}
\mathrm{BAI}_{y, i, c, k} & =p 0+h 1_{c}+\left(h 2_{c}+C_{y}\right) \times \mathrm{SBA}_{y, k}+p 1 \\
& \times T \operatorname{thin}_{y, k}+p 2 \times T \operatorname{thin}_{y, k}^{2}+h 3_{c} \times \text { Dratio }_{y, i}+p 3 \\
& \times \operatorname{Dratio}_{y, i}^{2}+h 4_{c} \times \mathrm{BAL}_{y, i}+A_{i}+B_{y}+E_{y, i, c, k}
\end{aligned}
$$

where $p 0$ is the overall intercept, $h 1$ to $h 4$ are parameters associated with the crown class effect on BAIs and $p 1$ to $p 3$ are parameters adjusting the covariates with a fixed effect.

The terms included were as follows:

- Crown class (a fixed effect);

- Stand basal area (log-transformed) (SBA, $\ln \left(\mathrm{m}^{2} \mathrm{ha}^{-1}\right), \mathrm{a}$ covariate with a fixed effect);

- Basal area of the largest trees (BAL, $\mathrm{mm}^{2}$, a covariate with a fixed effect), average basal area of the five largest trees in the plot;

- Ratio between diameter of the subject tree and the mean quadratic diameter (Dratio, unitless, a covariate with a fixed effect) included with a quadratic effect;

- Number of years since the last thinning (Tthin, year, a covariate with a fixed effect) included with a quadratic effect;

- Tree effect on the intercept $\left(A, \mathrm{~mm}^{2}\right.$ year ${ }^{-1}$, a random effect, $\left.\operatorname{Var}\left(A_{i}\right)=\sigma_{A}^{2}\right)$, the between-tree variance of the overall intercept;

- Year effect on the intercept $\left(B, \mathrm{~mm}^{2}\right.$ year ${ }^{-1}$, a random effect $\operatorname{Var}\left(B_{y}\right)=\sigma_{B}^{2}$ ), the between-year variance of the overall intercept;

- Year effect on the SBA slope $\left(C, \mathrm{~mm}^{2} \mathrm{~m}^{2} \mathrm{ha}^{-1}\right.$ year ${ }^{-1}, \mathrm{a}$ covariate with a random effect, $\left.\operatorname{Var}\left(C_{y}\right)=\sigma^{2}{ }_{C}\right)$, the between-year variance of the SBA slope.

$\operatorname{Var}\left(E_{\mathrm{y}, \mathrm{i}, \mathrm{c}, \mathrm{k}}\right)=\sigma_{E}^{2}$ is the residual variance within tree and year. $A, B, C$, and $E$ are assumed to follow normal distributions with zero means. We retained a first-order autoregressive model (AR(1) equivalent to $\operatorname{ARMA}(1,0)$, Fallour-Rubio et al. 2009) as the covariance structure for the error terms and the residual variance was assumed proportional to the predicted BAIs (power exponent=1). The modeling was performed with the MIXED procedure of SAS software and the parameters were estimated with the REML method (Littell et al. 2006), except when simplifying the fixed part of the model when ML was used (Zuur et al. 2009). The KenwardRoger correction was used to compute the degrees of freedom (Kenward and Roger 2009) required to test for the significance of fixed effects.

\subsubsection{Growth response to annual climate}

In Eq. 1, the inter-annual growth variability is isolated from the raw BAI signal and characterized by a year effect on the overall average BAI $(B)$ and a year effect on the SBA slope $(C)$. Assuming that the inter-annual growth variability is driven by annual climate, the yearly estimates of $B$ and $C$ thus allowed quantifying the effect of a SBA decrease on the growth responses to the different annual climatic conditions. We compared the predicted growth response to annual climate for different competition intensities (SBA $=55,40,30,20,15$, and $10 \mathrm{~m}^{2}$ ha $^{-1}$ ). Average comparisons were conducted separately for the years displaying strong (named positive years) and low (named negative years) growth: a year was considered positive if its predicted growth response to climate at $\mathrm{SBA}=55 \mathrm{~m}^{2} \mathrm{ha}^{-1}$ (average of the control plot) was higher than the average, negative otherwise.

Additionally, a pointer year analysis was conducted on the fixed-effect model residuals. Pointer years were identified when the average of the BAIs from the control plot was negative and if at least $75 \%$ of the trees had a BAI reduced by $10 \%$ or more compared with the previous year (Lebourgeois et al. 2005). Plot responses were compared through the average of the fixed-effect residual values of each pointer year, the mean fixed-effect residual values of the subsequent year and the mean fixed-effect residual values over the five subsequent years. As an attempt to assess how annual climate drove growth reductions at this site, climatic variables were used as regressors to predict the fixed-effect residual values (for the years 1990 to 2010, $n=21$ ) of the control plot in a multiple linear regression model. The climatic covariates included precipitation; mean, maximum and minimum temperature; and the De Martonne aridity index; these variables were expressed as monthly and annual averages, and as seasonal means over the growth period (March to July) and the autumn months (October to December). For a given year $y$, the climatic variables of the years $y$ and $y-1$ were considered.

The standard deviation (SD) and the Gini coefficient (GC) of the raw recorded growth series were calculated to compare the growth sensitivity to annual climate among plots and crown classes. SD is an absolute measurement of the growth sensitivity, whereas GC is a relative index, quantifying the sensitivity scaled by mean and sample size (Biondi and Qeadan 2008). SD and GC were calculated for each tree and averaged in a second step. For managed plots, SD and GC were calculated over sub-periods excluding year of thinning, the resulting values being averaged with a weight for the duration of the sub-period.

\section{Results}

\subsection{Homogeneity of growth conditions among plots}

The site indexes of the four plots had similar values (Table 1), indicating similar site productivity and thus a homogeneous 
environment among plots. Accordingly, the mean $\mathrm{CBH}$ of the 5 crown classes - measured before the initiation of the experiment - did not differ significantly among plots (Table 1). We therefore considered only thinning-induced effects at the plot level in the growth model.

\subsection{Tree growth drivers and variance partitioning}

Several tree- and stand-level variables entered the final model to take into account the changes in tree growth conditions during the experiment (Table 3). Stand basal area, quantifying the competition intensity, was negatively associated to annual growth. Dratio a measure of the competitive ranking of a tree within a plot, and $T$ thin entered the model with quadratic effects. The higher growth capacity of bigger trees compare to small ones was accounted for by the positive coefficient of BAL: for a given SBA, trees from a plot with lower stem density and higher stem sizes had higher predicted BAIs. SBA, Dratio and BAL had significant interactions with the crown class factor, indicating that the association between competition-related variables and the annual growth varied with the social position of the trees. The correlation between the variables entered in the final model was low (Table S2) and the variance inflation factors calculated on centered data was less than 3.5 for each predictor (Table 3), ensuring a tolerable multicollinearity among the variables (Belsley et al. 2005). The between-tree $\left(\sigma_{A}\right)$ and between-year $\left(\sigma_{B}\right)$ variances explained approximately 23 and $48 \%$ of the intercept

Table 3 Summary of the fitted linear mixed model of BAI. VIF is the variance inflation factor, calculated on centered data. The symbols in the sign column indicate the sign of the estimate value(s) for the corresponding variable. All estimate values are available in Table S3

\begin{tabular}{|c|c|c|c|c|}
\hline & VIF & $F$ value & $P$ value & Sign \\
\hline Crown class & & 615.6 & $<0.001$ & \\
\hline SBA & 1.4 & 259.7 & $<0.001$ & - \\
\hline$T$ thin & 3.2 & 22.8 & $<0.001$ & - \\
\hline Tthin ${ }^{2}$ & 3.1 & 72.4 & $<0.001$ & - \\
\hline Dratio & 1.0 & 5158.2 & $<0.001$ & + \\
\hline Dratio $^{2}$ & 1.1 & 544.6 & $<0.001$ & + \\
\hline BAL & 1.8 & 830.2 & $<0.001$ & + \\
\hline Crown class $\times$ SBA & & 257.1 & $<0.001$ & \\
\hline Crown class $\times$ Dratio & & 85.9 & $<0.001$ & \\
\hline Crown class $\times$ BAL & & 120.9 & $<0.001$ & \\
\hline$\sigma_{\mathrm{A}}=630 \quad \sigma_{\mathrm{B}}=903$ & $\sigma_{\mathrm{E}}=689$ & & & \\
\hline $\mathrm{AIC}=30791.34$ & $\log$ Lik. $=-15367.82$ & & & \\
\hline
\end{tabular}

$B A I$ basal area increment, $S B A$ stand basal area (log-transformed, $\left.\ln \left(\mathrm{m}^{2} \mathrm{ha}^{-1}\right)\right)$, $T$ thin the number of years since the last thinning (year), Dratio the ratio between diameter of the subject tree and the mean quadratic diameter (unitless), $B A L$ the basal area of the largest trees $\left(\mathrm{mm}^{2}\right)$. See further explanations in the main text variance, respectively. The final model residuals showed no departure from the assumption of normally distributed error with homogenous variance (result not shown). The graphical agreement between the means of the annual observations and the fixed-effect model predictions is displayed in Fig. 3.

\subsection{Predicted effect of thinning on the growth response} to annual climate

A decrease in SBA enhanced the predicted growth response to annual climate in negative years, indicating that thinning dampened the negative impact on growth when the year was constraining (Fig. 4). This benefit of thinning was only significant for heavy thinning as the minimum SBA range for significant difference in growth response was 40 to $15 \mathrm{~m}^{2} \mathrm{ha}^{-1}$. Consequently, a significant thinning-induced improvement of the growth response to climate was observed on plots where only the dominant and co-dominant crown classes remained in the stand (Table 2, Fig. 2). Contrastingly, the growth enhancement observed in positive years was reduced for low SBAs, but no significant effects were reported (Fig. 4).

\subsection{Pointer year analysis}

The best AIC climatic model with two covariates was as follows:

Residuals $=-619.1+0.33 R(-1)+11.07 \mathrm{DMI}$

with $\mathrm{R}(-1)$ representing the autumn rainfall of the previous year and DMI the De Martonne index averaged over the growth period (March to July).

Rainfall and water balance (approximated by the De Martonne index) had a positive effect on growth. The model explained an important part of the inter-annual variability of the LMM residuals $\left(R^{2}=0.68, \mathrm{RMSE}=94.6, F=32.5, P\right.$ value $<0.001$ ), with a predominant importance of the growth period DMI (partial $R^{2}=0.55$ ). Growth reductions in negative pointer years, identified as 1994, 1997, 2002, and 2005, were well predicted by the climatic model (Fig. 5).

The growth of the dominant crown classes was proportionally less affected by drought in plots where a thinning had recently decreased the stem number below 550 trees per hectare (i.e., in 1994 and 2002, in plots 1 and 2; respectively, Figs. 2 and 6; complete results in Table S4). Additionally, the heaviest thinning improved post-drought resilience of the stand during a decade (growth was proportionally higher in 1995 and over the periods 1995-1999 and 1998-2002 in plot 1). The benefits of thinning were maintained by successive operations as shown by the significantly higher growth of plot 1 in 1994 and 2003. The same pattern was found 


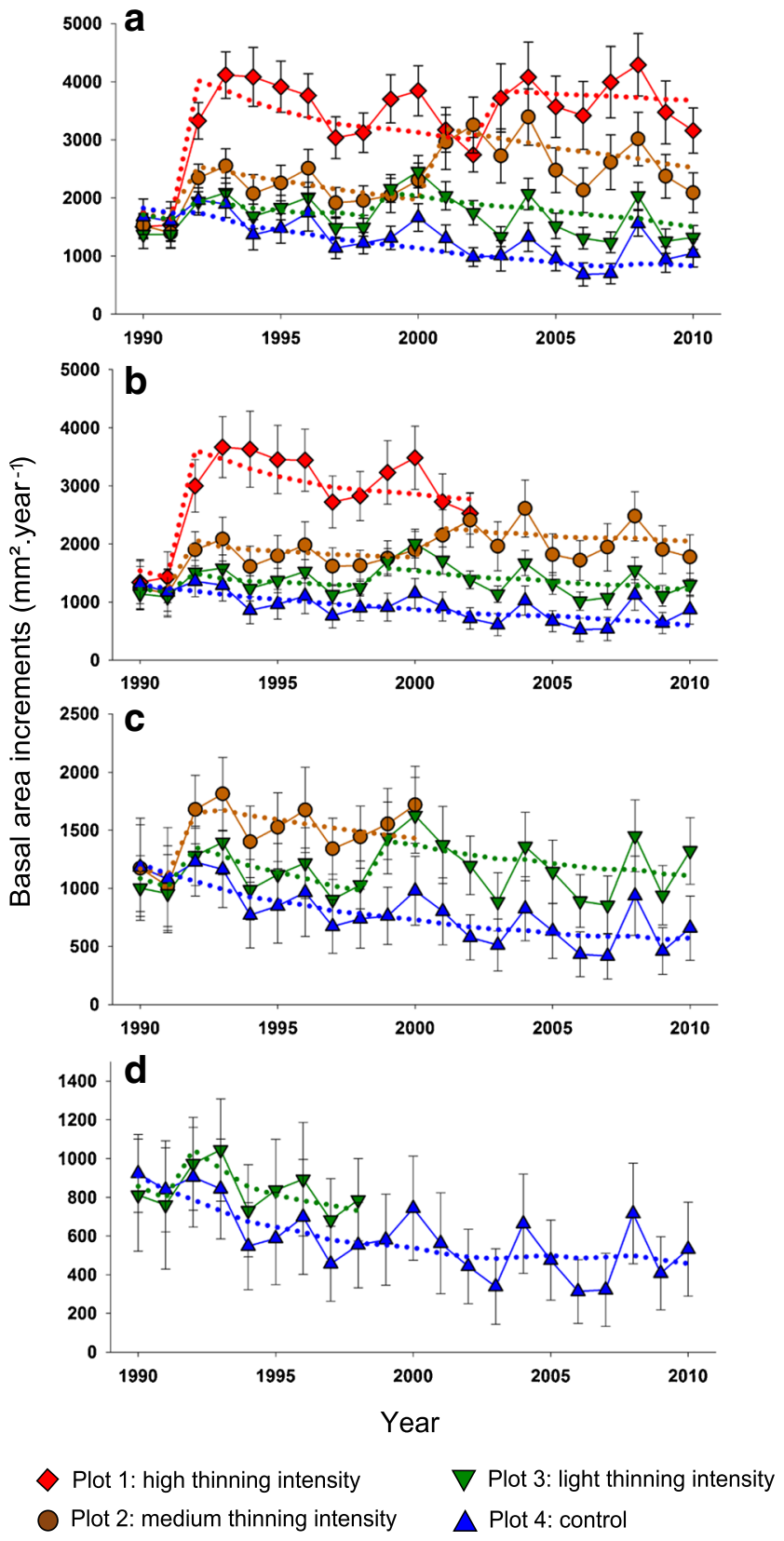

Fig. 3 Evolution of the observed averaged basal area increments (BAIs, solid lines) and averaged fixed-effect predictions from the linear mixed model (dotted lines), for the dominant class (a), co-dominant class (b), intermediate class (c), and the overtopped class (d). Error bars are standard deviations of the observed BAIs. For a better readability, error bars of the predictions are not represented

in the dominant and co-dominant crown classes (Table S4).

\subsection{Growth sensitivity to annual climate}

The SD and GC values were positively associated with thinning intensity in every crown class (Table 4). SD and GC increased significantly for thinning intensities that yielded a

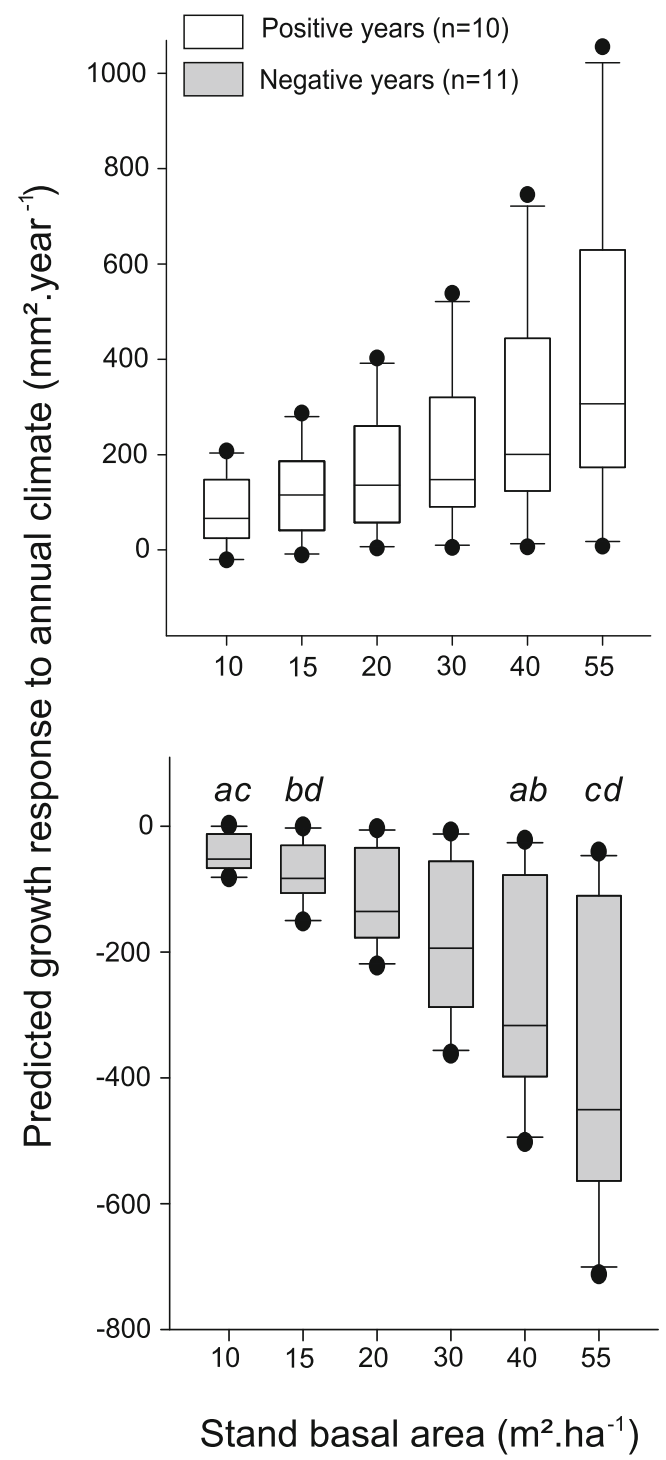

Fig. 4 Predicted growth response to annual climate (from 1990 to 2010) under contrasted stand basal areas. Predictions are obtained from $B$ and $C$ estimates in Eq. 1. For a given year $i$ : Prediction $_{i}=B_{i}+C_{\mathrm{i}} \times \ln (\mathrm{SBA})$, where SBA is stand basal area. Positive and negative years correspond to years with high growth and low growth, respectively (see main text). Similar letters indicate a significant difference at the $5 \%$ probability level in a Wilcoxon-Mann-Whitney test. No significant differences were reported for positive years

SBA lower than $19.5 \mathrm{~m}^{2} \mathrm{ha}^{-1}$ (or a stand density below 1200 trees $\mathrm{ha}^{-1}$ ), i.e., below the value attained in plot 3 (Table 2). Moreover, inter-annual growth sensitivity was significantly higher for the dominant classes, regardless of the thinning treatment.

\section{Discussion}

We used a tree growth model to achieve an efficient competition-based detrending of annual growth series in the context of thinning-induced sharp competition changes. The 


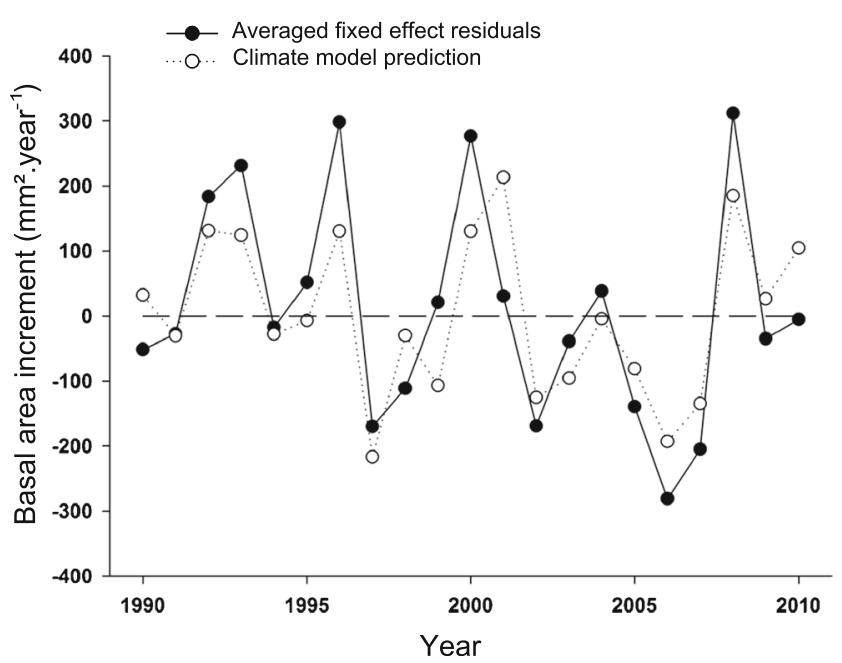

Fig. 5 Comparison of the averaged linear mixed model fixed-effect residuals of the control plot and the climatic model predictions

fixed part of the linear mixed model performed satisfactorily against observed BAIs in all crown classes and thinning treatments (Fig. 3), despite occasional discrepancies (e.g., in average, the model underestimated the growth of the dominant crown class in the control plot). Unbiased fixed-effect predictions were required to isolate the climate-driven component of the growth time series from the effects of tree age and thinning. Without additional ecophysiological measurements, the interpretation of the retained fixed effects is not straightforward because the dendrometric variables used in the LMM are proxies accounting for complex functional responses (Brooks and Mitchell 2011; Sohn et al. 2013). In particular, the predicted transient growth increase induced by thinning likely accounts for an improvement of the resource availability (Nambiar and Sands 1993; Bréda et al. 1995), for the enhancement of the remaining tree crown areas (Pretzsch 2014) and/or for the possible mobilization of stored non-structural carbohydrates in support of growth. The LMM provided a sound framework to disentangle management effects from the climate-driven signal and to quantify the interaction between thinning and climate on growth. LMMs have thus the potential to complement classical dendrochronological analyses as they can be used to separate signal components whose periods are not fully included in the growth series: competition effects were evaluated in this study using a dataset spanning two decades i.e., less than the signal period induced by thinning (Misson et al. 2003).

\subsection{Crown class modulation of the climate-growth} relationship

Summer drought has been widely reported as the most important factor limiting tree growth and productivity in the Mediterranean area. In line with these results, the aridity during the growth period was the principal factor controlling the annual variability of growth at our site, with a secondary carry-over effect of the previous year rainfall (Fig. 5). The increase in the absolute annual sensitivity of growth (quantified by the standard deviation) when average tree growth increases is a long known result in forest sciences (Cook 1985) and has been taken into account in the statistical modeling. Conversely, the reported increase in the relative annual sensitivity of growth (quantified by the Gini coefficient) of the two dominant crown classes highlights a different functional response to climate of dominant trees, regardless of the thinning treatment. The literature reports contradictory results regarding the crown class modulation of the tree growth responses to annual climate: certain studies report suppressed trees to be more sensitive to rainfall variability (De Luis et al. 2009; Olivar et al. 2013), whereas others report a greater sensitivity of the dominant trees, in line with our results (Martín-Benito et al. 2008; Mérian and Lebourgeois 2011). Performing a multispecies analysis along a wide climatic gradient, Mérian and Lebourgeois (2011) reported that larger trees of shade-tolerant species, such as $C$. atlantica, were significantly more sensitive to summer drought than smaller trees. This difference increased with increasing site xericity. The buffer effect on environmental conditions provided by dominant tree canopy (Aussenac 2000) could be more important at water-limited sites, thereby explaining that the suppressed trees at our study site are less sensitive to the inter-annual water balance variability. In another view, the lower growth sensitivity of suppressed trees is due to a loss of plastic capacity in those trees strongly constrained by competition (Linares et al. 2010). A third plausible explanation of the greater sensitivity of large trees to climatic stress is their higher water needs and the higher risk of cavitation that they face due to their longer xylem path (Bigler and Veblen 2009). We reported a significant increase in sensitivity between the co-dominant and the dominant classes, regardless of the thinning treatment. Moreover, the sensitivity of a dominant crown class increased with thinning intensity. As microclimate buffering and competition constraints are expected to be rather similar between the two most dominant classes, we assumed that the crown-class modulation of the growth response to annual climate was driven primarily by size-related constraints on tree functioning in this context (D'Amato et al. 2013).

\subsection{Effect of thinning on the climate-growth relationship}

Thinning was found to significantly modulate the growth response to annual climate of the dominant and co-dominant crown classes of cedar stands. Using a contrasted approach, Gea-Izquierdo et al. (2009) and Piutti and Cescatti (1997) also 
Fig. 6 Growth responses to three pointer years (1994, 1997, 2002, from top to bottom) in the dominant crown class. Pointer years (underlined) correspond to abrupt negative changes in the growth patterns. Results are presented for pointer year (left panel), 1 year after pointer year (middle panel) and post-pointer year period (right panel), when no thinning occurred. The boxed numbers refer to the corresponding plot. Plots with a "*” differed significantly from the others (at the $5 \%$ probability level in a pairwise Tukey test). Bottom numbers $(X)$ means " $\mathrm{X}$ years since the last thinning"

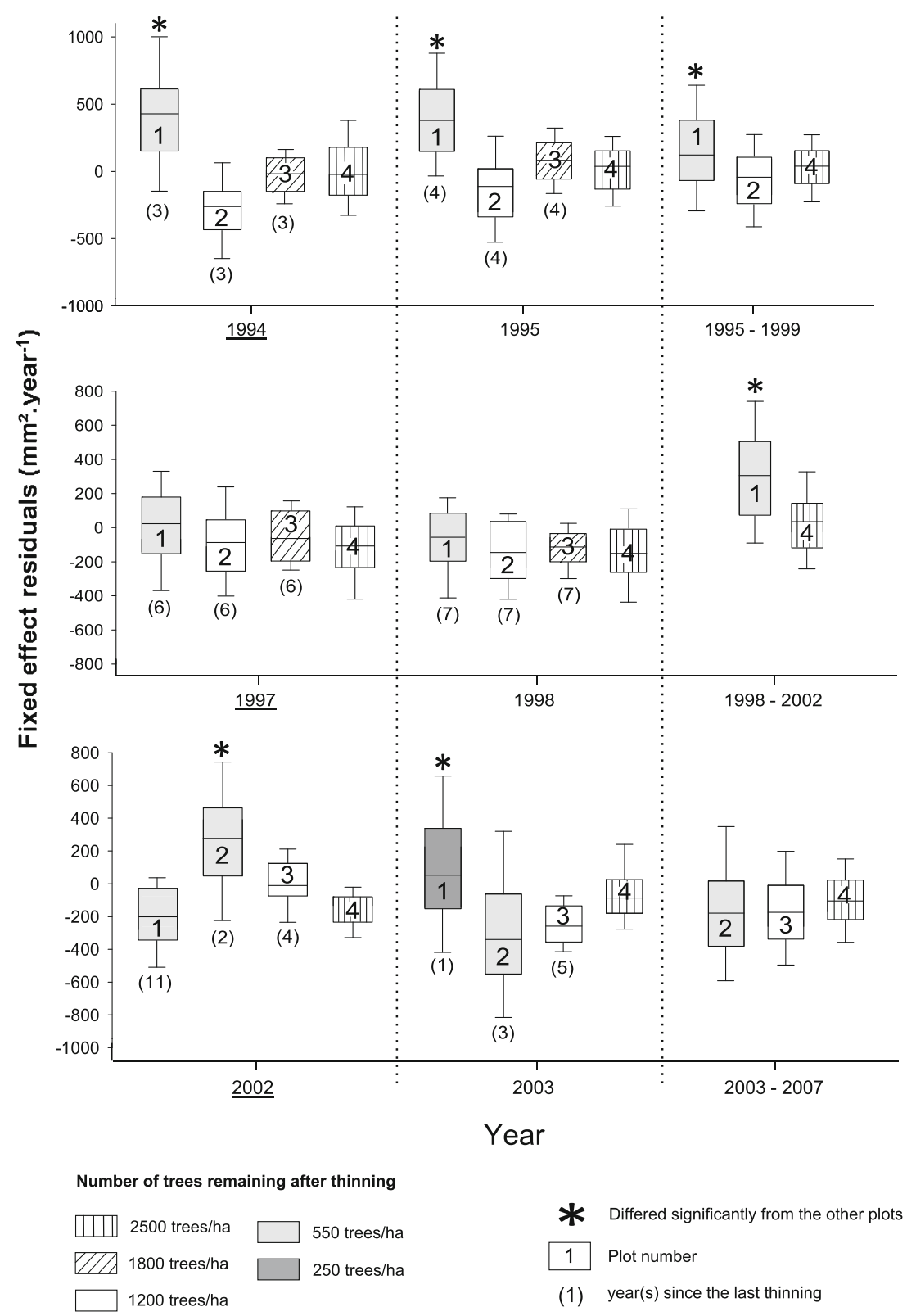

highlighted differences in the correlation between climate variables and annual growth among trees experiencing different competition intensities. Both studies reported a greater effect of water deficit (low precipitation and high temperatures) in denser stands. In line with these results, heavy thinning reduced the negative effect of drought years on dominant tree growth in our experiment. Note that only a heavy stand basal area reduction (40 to $15 \mathrm{~m}^{2}$ ), which is beyond the current prescription (Courbet et al. 2007), significantly altered the climate-growth relationship. This suggests that light thinning does not affect the functional response of trees facing constraining years in dry sites, where inter-tree competition for water is strong (Olivar et al. 2013). Accordingly, the growth of heavily thinned stands (to less than 550 trees per hectare) was less affected by negative pointer years during the 4-5 years following thinning in both absolute (Fig. 6) and relative terms. This result agrees with Misson et al. (2003) and Sohn et al. (2013), who found a smaller relative growth reduction induced by severe drought in recently thinned stands. Conversely, Timbal (2002) reported a greater drought-induced reduction in the absolute growth of heavily thinned stands. Kohler et al. (2010) and McDowell et al. (2006) also reported this higher absolute decrease but additionally emphasized the occurrence of a lower relative decline, in line with our results. The contradictory literature results regarding the effect of thinning on the drought-induced absolute growth decline are most likely due to variation in the thinning and drought intensities imposed in the different studies. The ecological traits of the different studied species could also explain these conflicting results. Indeed, different strategies in the adaptation of the water conductivity system to 
Table 4 Growth sensitivity to annual climate. Within a given crown class, values with different Latin letters differed significantly (at the $5 \%$ probability level in a pairwise Tukey test). Within a given plot, values with different Greek letters differed significantly (at the $5 \%$ probability level in a type I test)

\begin{tabular}{llllll}
\hline & & Plot 1 & Plot 2 & Plot 3 & Plot 4 \\
\hline Dominant class & SD & $723.3^{\mathrm{a}}$ & $549.4^{\mathrm{b}}{ }_{\alpha}$ & $387.0^{\mathrm{c}}{ }_{\alpha}$ & $385.6^{\mathrm{c}}$ \\
& GC & $0.08^{\mathrm{a}}$ & $0.06^{\mathrm{b}}{ }_{\alpha}$ & $0.04^{\mathrm{c}}{ }_{\alpha}$ & $0.04^{\mathrm{c}}{ }_{\alpha}$ \\
Co-dominant class & SD & & $450.4^{\mathrm{a}}{ }_{\beta}$ & $307.3^{\mathrm{b}}{ }_{\beta}$ & $289.2^{\mathrm{b}}{ }_{\beta}$ \\
& GC & & $0.05^{\mathrm{a}}{ }_{\beta}$ & $0.03^{\mathrm{b}}{ }_{\beta}$ & $0.03^{\mathrm{b}}{ }_{\beta}$ \\
Intermediate class & SD & & & $294.9^{\mathrm{a}}{ }_{\beta}$ & $264.5 \mathrm{a}^{\mathrm{a}}{ }_{\beta}$ \\
& GC & & $0.03^{\mathrm{a}}{ }_{\beta}$ & $0.03^{\mathrm{a}}{ }_{\beta}$ \\
Overtopped class & SD & & & & $194.4_{\gamma}$ \\
& GC & & & & $0.02{ }_{\gamma}$ \\
Supressed class & SD & & & & $178.3 \gamma$ \\
& GC & & & & $0.03 \gamma$ \\
\hline
\end{tabular}

$S D$ standard deviation, $G C$ Gini coefficient

drought (Eilmann et al. 2009) or in the capture of resources (Cuny et al. 2012) are associated with distinct growth responses to environmental factors among species. Collectively, our results confirm that the increased water availability in recently heavily thinned stands of Atlas cedar allows trees to maintain higher growth during drought in our site. We additionally reported that high thinning intensity led to a greater post-pointeryear growth recovery of the dominant classes for a decade. This medium-term consequence of thinning has been reported in different species (Misson et al. 2003; Kohler et al. 2010; Sohn et al. 2013) and likely resulted from tree structural changes, such as increased foliage area and fine root biomass (Sohn et al. 2013). Benefits of thinning could be maintained by successive operations, as previously suggested by Le Goff and Ottorini (1993) and Timbal (2002) in Fagus and Pinus, respectively.

\subsection{Management perspectives}

Tree growth has often been shown to be a proxy for tree vitality, and numerous studies report that dying trees exhibit lower growth (Bigler and Bugmann 2004). Consequently, because thinning enhances the growth of remaining trees, it has been advocated to reduce drought effects and the mortality risk for different species and sites (e.g., Misson et al. 2003; Kohler et al. 2010). As an increasing drought frequency is projected by climate models, the reported ability of thinning to limit the negative impact on growth when the year is constraining confirms that silviculture could play a role in the adaptation of $C$. atlantica stands to climate change. Repeated heavy thinning has thus the potential to limit the risk related to drought by reducing both growth sensitivity to summer water deficit and the length of the forest rotation.
However, except for a short post-thinning period, management increased the sensitivity of relative growth to annual climate variability. This result, which we interpreted as the effect of size-related constraints on cedar growth, agrees with a previous study reporting that Pinus with greater growth were proportionally more affected by drought (Martínez-Vilalta et al. 2012). The interpretation of this higher sensitivity from the viewpoint of the ability of cedar to cope with drought effects is not straightforward, and we still lack a conceptual framework linking the growth signal features to life traits (Cuny et al. 2012) and demography (Martínez-Vilalta et al. 2012). Indeed, previous studies produced seemingly contradictory results, reporting higher mortality rates for trees showing highly variable growth (Suarez and Ghermandi 2004) or a weaker correlation between the growth of the dying trees and the climate variables (Linares et al. 2010). As recent reports suggest a lower capacity of large trees to overcome severe drought (Bigler and Veblen 2009), the long-term effect on thinning on the ability of mature cedar stands to survive extreme water stress events need further investigations.

\section{Conclusion}

This research contributes to the analysis of the poorly studied interaction between stand structure and annual climate on tree growth. Our results suggest that heavy thinning mitigates the effect of drought on C. atlantica in a site of the southern French Alps. This site is characterized by a Mediterranean mountain climate with important annual rainfall and a low soil water holding capacity. In Europe, forest is often located on poor soils, where no profitable agriculture is possible (Chakir and Le Gallo 2013). Our study site is therefore representative of the growth conditions that will face the $C$. atlantica stands recently introduced in the northern Mediterranean zone and the temperate French territory in order to adapt forest to climate change. Our results regarding the stand density desirable to reduce the effect of drought on Atlas cedar functioning should now be integrated with the other relevant ecological factors impacted by thinning (e.g., regeneration and soil erosion) in order to design future management guidelines in these areas.

Acknowledgments We give warm thanks to Florence Courdier, William Brunetto, Frédéric Jean, Nicolas Mariotte and Norbert Turion, who collected the data and managed the study site. We are grateful to Claire Damesin, Nicolas K. Martin-StPaul and Pierre Mérian for their helpful comments. We thank Météo-France for providing weather data. The study was part of the French national project "Réseau Mixte Technologique AFORCE". We thank the editors and the anonymous reviewers for insightful comments on our manuscript.

Funding The study was funded by the "Institut National de la Recherche Agronomique". J.G. received a grant from the RMTAFORCE. 


\section{References}

Allen CD, Macalady AK, Chenchouni $\mathrm{H}$ et al (2010) A global overview of drought and heat-induced tree mortality reveals emerging climate change risks for forests. For Ecol Manage 259:660-684. doi:10. 1016/j.foreco.2009.09.001

Andreu L, Gutiérrez E, Macias M et al (2007) Climate increases regional tree growth variability in Iberian pine forests. Glob Chang Biol 13: 804-815

Aussenac G (2000) Interactions between forest stands and microclimate: ecophysiological aspects and consequences for silviculture. Ann For Sci 57:287-301

Barbeta A, Ogaya R, Peñuelas J (2013) Dampening effects of long-term experimental drought on growth and mortality rates of a Holm oak forest. Glob Chang Biol 19:3133-3144

Belsley DA, Kuh E, Welsch RE (2005) Regression diagnostics: identifying influential data and sources of collinearity. Wiley, New York

Benabid A (1994) Biogéographie phytosociologie et phytodynamique des cédraies de l'Atlas à Cedrus atlantica (Manetti). Ann Rech For Au Maroc 27:62-76

Bigler C, Bugmann H (2004) Predicting the time of tree death using dendrochronological data. Ecol Appl 14:902-914

Bigler C, Veblen TT (2009) Increased early growth rates decrease longevities of conifers in subalpine forests. Oikos 118:1130-1138

Biondi F, Qeadan F (2008) Inequality in paleorecords. Ecology 89:10561067

Bréda N, Granier A, Aussenac G (1995) Effects of thinning on soil and tree water relations, transpiration and growth in an oak forest (Quercus petraea (Matt.) Liebl.). Tree Physiol 15:295-306

Brooks JR, Mitchell AK (2011) Interpreting tree responses to thinning and fertilization using tree-ring stable isotopes. New Phytol 190: 770-782

Chakir R, Le Gallo J (2013) Predicting land use allocation in France: a spatial panel data analysis. Ecol Econ 92:114-125

Cook ER (1985) A time series analysis approach to tree ring standardization (dendrochronology, forestry, dendroclimatology, autoregressive process). The University of Arizona

Courbet F, Courdier J-M, Mariotte N, Courdier F (2007) Croissance, production et conduite des peuplements de cèdre de l'Atlas. Forêt Entrep 174:40-44

Cuny HE, Rathgeber CBK, Lebourgeois F et al (2012) Life strategies in intra-annual dynamics of wood formation: example of three conifer species in a temperate forest in north-east France. Tree Physiol 32: 612-625. doi:10.1093/treephys/tps039

D'Amato AW, Bradford JB, Fraver S, Palik BJ (2013) Effects of thinning on drought vulnerability and climate response in north temperate forest ecosystems. Ecol Appl 23:1735-1742

De Luis M, Novak K, Čufar K, Raventós J (2009) Size mediated climategrowth relationships in Pinus halepensis and Pinus pinea. Trees 23: 1065-1073. doi:10.1007/s00468-009-0349-5

Dobbertin M (2005) Tree growth as indicator of tree vitality and of tree reaction to environmental stress: a review. Eur J For Res 124:319 333

Eilmann B, Zweifel R, Buchmann N et al (2009) Drought-induced adaptation of the xylem in Scots pine and pubescent oak. Tree Physiol 29:1011-1020

Fallour-Rubio D, Guibal F, Klein EK et al (2009) Rapid changes in plasticity across generations within an expanding cedar forest. J Evol Biol 22:553-563. doi:10.1111/j.1420-9101.2008.01662.x

Fortin M, Daigle G, Ung C-H et al (2007) A variance-covariance structure to take into account repeated measurements and heteroscedasticity in growth modeling. Eur J For Res 126:573-585. doi:10.1007/ s10342-007-0179-1

Gea-Izquierdo G, Martín-Benito D, Cherubini P, Isabel C (2009) Climate-growth variability in Quercus ilex L. west Iberian open woodlands of different stand density. Ann For Sci 66: 802

Guillemot J, Delpierre N, Vallet P et al (2014) Assessing the effects of management on forest growth across France: insights from a new functional-structural model. Ann Bot 114:779-793. doi:10.1093/ $\mathrm{aob} / \mathrm{mcu} 059$

Kenward MG, Roger JH (2009) An improved approximation to the precision of fixed effects from restricted maximum likelihood. Comput Stat Data Anal 53:2583-2595

Kohler M, Sohn J, Nägele G, Bauhus J (2010) Can drought tolerance of Norway spruce (Picea abies (L.) Karst.) be increased through thinning? Eur J For Res 129:1109-1118

Le Goff N, Ottorini J-M (1993) Thinning and climate effects on growth of beech (Fagus sylvatica L.) in experimental stands. For Ecol Manage 62:1-14

Lebourgeois F, Bréda N, Ulrich E, Granier A (2005) Climate-tree-growth relationships of European beech (Fagus sylvatica L.) in the French Permanent Plot Network (RENECOFOR). Trees 19:385-401. doi: 10.1007/s00468-004-0397-9

Linares JC, Camarero JJ, Carreira JA (2010) Competition modulates the adaptation capacity of forests to climatic stress: insights from recent growth decline and death in relict stands of the Mediterranean fir Abies pinsapo. J Ecol 98:592-603. doi:10.1111/j.1365-2745.2010. 01645.x

Linares JC, Taïqui L, Camarero JJ (2011) Increasing drought sensitivity and decline of Atlas Cedar (Cedrus atlantica) in the Moroccan Middle Atlas forests. Forests 2:777-796

Littell RC, Milliken GA, Stroup WW et al (2006) SAS for mixed models. SAS Institute, Cary, 745

Martín-Benito D, Cherubini P, del Río M, Cañellas I (2008) Growth response to climate and drought in Pinus nigra Arn. trees of different crown classes. Trees 22:363-373

Martínez-Vilalta J, López BC, Loepfe L, Lloret F (2012) Stand-and treelevel determinants of the drought response of Scots pine radial growth. Oecologia 168:877-888

Martin-StPaul NK, Limousin J-M, Vogt-Schilb H et al (2013) The temporal response to drought in a Mediterranean evergreen tree: comparing a regional precipitation gradient and a throughfall exclusion experiment. Glob Chang Biol 19:2413-2426. doi:10.1111/gcb. 12215

McDowell NG, Adams HD, Bailey JD et al (2006) Homeostatic maintenance of ponderosa pine gas exchange in response to stand density changes. Ecol Appl 16:1164-1182

Mehtätalo L, Peltola H, Kilpela A, Ikonen V (2014) The response of basal area growth of scots pine to thinning: a longitudinal analysis of treespecific series using a nonlinear mixed-effects model. Ann For Sci 60:636-644

Mérian P, Lebourgeois F (2011) Size-mediated climate-growth relationships in temperate forests: a multi-species analysis. For Ecol Manage 261:1382-1391. doi:10.1016/j.foreco.2011. 01.019

Miina J (2000) Dependence of tree-ring, earlywood and latewood indices of Scots pine and Norway spruce on climatic factors in eastern Finland. Ecol Modell 132:259-273

Misson L, Vincke C, Devillez F (2003) Frequency responses of radial growth series after different thinning intensities in Norway spruce (Picea abies (L.) Karst.) stands. For Ecol Manage 177:51-63

Nambiar EKS, Sands R (1993) Competition for water and nutrients in forests. Can J For Res 23:1955-1968

Olivar J, Bogino S, Rathgeber C, et al. (2013) Thinning has a positive effect on growth dynamics and growth-climate relationships in Aleppo pine (Pinus halepensis) trees of different crown classes. Ann For Sci 1-10

Piutti E, Cescatti A (1997) A quantitative analysis of the interactions between climatic response and intraspecific competition in European beech. Can J For Res 27:277-284. doi:10.1139/x96-176 
Pretzsch H (2014) Canopy space filling and tree crown morphology in mixed-species stands compared with monocultures. For Ecol Manage 327:251-264

Roman-Amat B (2007) Préparer les forêts françaises au changement climatique. Rapp. à MM. les Minist. l'Agriculture la Pêche l'Ecologie, du Développement l'Aménagement Durables

Ruffault J, Martin-StPaul NK, Rambal S, Mouillot F (2013) Differential regional responses in drought length, intensity and timing to recent climate changes in a Mediterranean forested ecosystem. Clim Chang 117:103-117

Skovsgaard JP, Vanclay JK (2008) Forest site productivity: a review of the evolution of dendrometric concepts for even-aged stands. Forestry 81:13-31. doi:10.1093/forestry/cpm041

Sohn JA, Gebhardt T, Ammer C et al (2013) Mitigation of drought by thinning: short-term and long-term effects on growth and physiological performance of Norway spruce (Picea abies). For Ecol Manag 308:188-197. doi:10.1016/j.foreco.2013.07. 048

Suarez ML, Ghermandi L (2004) Factors predisposing episodic droughtinduced tree mortality in Nothofagus-site, climatic sensitivity and growth trends. J Ecol 92:954-966

Timbal J (2002) Analyse rétrospective de la croissance radiale et mise en relation avec le bilan hydrique dans un dispositif d'intensité d'éclaircie de pin maritime dans les Landes de Gascogne. Ann For Sci 59:205-217

Williams AP, Allen CD, Macalady AK et al (2013) Temperature as a potent driver of regional forest drought stress and tree mortality. Nat Clim Chang 3:292-297

Zuur A, Ieno EN, Walker N, et al (2009) Mixed effects models and extensions in ecology with R. Springer 